\title{
Study of factors contributing to female infertility
}

\author{
Kiran Parsuram Shinde ${ }^{1 *}$, Nagasundari Krovi ${ }^{1}$, Pooja Gangadhar Dhutraj ${ }^{2}$
}

\begin{abstract}
${ }^{1}$ Department of Obstetrics and Gynaecology, South Central Railway Hospital, Secunderabad, Telangana, India
${ }^{2}$ Department of PSM, LTMMC and GH, Sion, Mumbai, Maharashtra, India
\end{abstract}

Received: 10 May 2021

Accepted: 03 June 2021

\section{*Correspondence:}

Dr. Kiran Parsuram Shinde,

E-mail: shindek94@gmail.com

Copyright: (C) the author(s), publisher and licensee Medip Academy. This is an open-access article distributed under the terms of the Creative Commons Attribution Non-Commercial License, which permits unrestricted non-commercial use, distribution, and reproduction in any medium, provided the original work is properly cited.

\section{ABSTRACT}

Background: Infertility is a global issue in reproductive health. All over the world, infertility is viewed as a social stigma, which causes social, economic and psychological consequences.

Methods: A prospective, observational study was conducted at south central railway hospital, Secunderabad in 100 women aged between 18-40 years with complaints of primary and secondary infertility. We aimed to find the incidence of different causes of infertility in the females attending Gynaecology OPD over a period of 2 years.

Results: Different causes of infertility were studied. In the present study ovarian factors (50\%) was the most common factor for infertility followed by tubal factors (22\%), uterine factors (20\%) and peritoneal factors (19\%) respectively. Conclusions: PCOS was found to be a contributing factor in both primary and secondary infertility, maybe because of increased sedentary lifestyle and physical inactivity and the study population being from an urban background.

Keywords: Infertility, Primary infertility, Secondary infertility, PCOS

\section{INTRODUCTION}

Infertility is a global issue in reproductive health. All over the world, infertility is viewed as a social stigma, which causes social, economic and psychological consequences. Infertility is a common condition, affecting 10 to 15 percent of reproductive-aged couples. Of note, even without treatment, approximately half of women will conceive in the second year of attempting. Although the prevalence of infertility is believed to have remained relatively stable during the past 40 years, the demand for infertility evaluation and treatment has increased. ${ }^{1}$

According to recent studies by the WHO, approximately $8-10 \%$ of couples face the problem of infertility. Globally, this means that 50-80 million people are facing the problem of getting an integrated family. ${ }^{2}$ In India, the rate of infertility has decreased by $7.7 \%$ from NFHS-2 to NFHS-3. It is around 2\% in NFHS-2 and around $1.85 \%$ in NFHS-3. Infertility has been defined as the couple who has not conceived after 12 months of contraceptive-free intercourse if the female is under the age of 34 (12 months is the lower reference limit for time to pregnancy (TTP) by the WHO. ${ }^{3}$ The couple has not conceived after 6 months of contraception-free intercourse if the female is over the age of 35. Infertility further classified as primary infertility, in which no previous pregnancies have occurred and secondary infertility, in which a prior pregnancy, although not necessarily a live birth has occurred.

The present study was conducted with the aim to find the incidence of different causes of infertility in the females attending gynaecology outpatient department (OPD) at south central railway hospital, Secunderabad.

\section{METHODS}

A prospective, observational study was conducted at south central railway hospital, Secunderabad in 100 women aged between 18-40 years with complaints of primary and secondary infertility coming to gynaecology OPD with a desire to conceive from August 2016 to February 2018. 
Approval for the study was taken by the ethics and scientific committee of south central railway hospital, Secunderabad. The inclusion criteria for the study was females of age 18-40 years with primary and secondary infertility with no male infertility factor or other chronic medical disorders (e.g. SLE, cancer). The consent was taken in a predetermined format in their mother tongue. A detailed history was obtained from enrolled women about their menstrual, obstetrics and medical history. Careful general and systemic examinations were done, particularly pelvic examination for clinical diagnosis. All clinical features, physical examination findings were documented. All relevant investigations like $\mathrm{CBC}$, blood glucose, thyroid profile, viral serology were performed. Ultrasonography (USG) was done for evaluation of pelvic organs (uterine cavity, endometrial thickness and for any adnexal pathology). Hystero-salphingography (HSG) was done for tubal patency and structural abnormality in the uterine cavity. Hormonal studies (FSH, LH, thyroid profile and prolactin) were done. Hysterolaparoscopy was done in patients that needed further evaluation and results were documented. Data was entered in Microsoft excel 2007 and analysed using descriptive statistics, in the form of frequency, charts and percentage with help of SPSS version 18 .

\section{RESULTS}

In the present study, 62 cases $(62 \%)$ were primarily infertile and 38 cases (38\%) were secondarily infertile women which are graphically presented in Figure 1. Majority of women with primary $(74.19 \%)$ and secondary infertility $(52.63 \%)$ had duration of infertility of $12-60$ months.
Most women with primary infertility belonged to the age group of 21-25 years (45.16\%) and secondary infertility to the age group of $26-30$ years $(42.10 \%)$. The mean age of infertile women was 28.13 years; for primary infertility, the mean age was 27.53 years and for secondary infertility, the mean age was 29.10 years. This age wise distribution is presented in Figure 2.

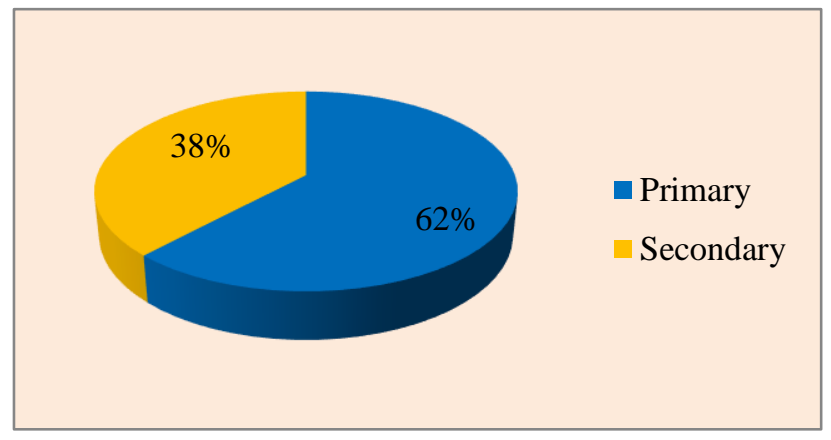

Figure 1: Types of infertility

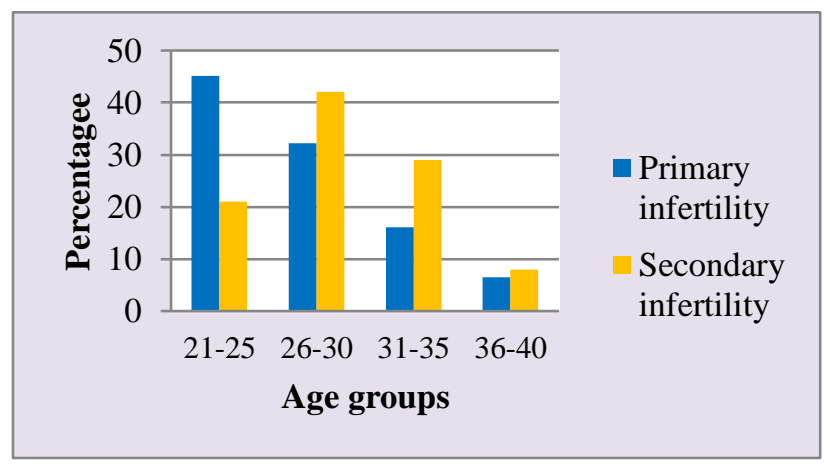

Figure 2: Age-wise distribution of patients.

Table 1: Causes of infertility $(\mathrm{N}=100)$.

\begin{tabular}{|lllllll|}
\hline \multirow{2}{*}{ Causes of infertility } & \multicolumn{2}{l}{ Primary $(\mathbf{N}=\mathbf{6 2})$} & \multicolumn{2}{l|}{ Secondary $(\mathbf{N}=\mathbf{3 8})$} & \multicolumn{2}{c|}{ Total $(\mathbf{N}=\mathbf{1 0 0})$} \\
\cline { 2 - 7 } & Number & $\mathbf{\%}$ & Number & $\mathbf{\%}$ & Number & \% \\
\hline Ovarian factor & 34 & 54.83 & 16 & 42.10 & 50 & 50 \\
\hline Tubal factor & 13 & 20.96 & 9 & 23.6 & 22 & 22 \\
\hline Uterine factor & 13 & 20.96 & 7 & 18.4 & 20 & 20 \\
\hline Peritoneal factor & 13 & 20.96 & 6 & 15.7 & 19 & 19 \\
\hline Unexplained & 9 & 14.51 & 11 & 28.9 & 20 & 20 \\
\hline
\end{tabular}

Table 2: Laparoscopically identified pathology of infertility $(N=78)$.

\begin{tabular}{|c|c|c|c|c|}
\hline \multicolumn{2}{|c|}{ Causes of infertility } & $\begin{array}{l}\text { Primary infertility } \\
(\mathrm{N}=49) \text { frequency }(\%)\end{array}$ & $\begin{array}{l}\text { Secondary infertility } \\
(\mathrm{N}=29) \text { frequency }(\%)\end{array}$ & $\begin{array}{l}\text { Total frequency }(\%) \\
(\mathrm{N}=78)\end{array}$ \\
\hline \multirow{6}{*}{$\begin{array}{l}\text { Ovarian } \\
\text { factor }\end{array}$} & PCOS & $12(24.48)$ & $6(20.68)$ & $18(23.04)$ \\
\hline & Simple cyst & $1(2.04)$ & $1(2.04)$ & $2(2.56)$ \\
\hline & Chocolate cyst & $4(8.16)$ & $1(2.04)$ & $5(6.41)$ \\
\hline & Complex cyst & $4(8.16)$ & $1(2.04)$ & $5(6.41)$ \\
\hline & Streak ovaries & $1(2.04)$ & 0 & $1(2.04)$ \\
\hline & Total & $22(44.89)$ & $9(31.03)$ & $31(39.74)$ \\
\hline \multirow{3}{*}{$\begin{array}{l}\text { Tubal } \\
\text { factor }\end{array}$} & B/L block & $8(16.32)$ & $2(6.89)$ & $10(12.82)$ \\
\hline & U/L block & $2(4.08)$ & $5(17.24)$ & $7(8.97)$ \\
\hline & Hydrosalpinx & 0 & $2(6.89)$ & $2(2.56)$ \\
\hline
\end{tabular}




\begin{tabular}{|c|c|c|c|c|}
\hline \multicolumn{2}{|c|}{ Causes of infertility } & \multirow{2}{*}{$\begin{array}{l}\text { Primary infertility } \\
(\mathrm{N}=49) \text { frequency }(\%) \\
3(612)\end{array}$} & \multirow{2}{*}{$\begin{array}{l}\text { Secondary infertility } \\
(\mathrm{N}=29) \text { frequency }(\%) \\
0\end{array}$} & \multirow{2}{*}{$\begin{array}{l}\text { Total frequency (\%) } \\
(\mathrm{N}=78) \\
3(3.84)\end{array}$} \\
\hline & TO mass & & & \\
\hline & Peri tubal & $1(2.04)$ & $1(3.44)$ & $2(2.56)$ \\
\hline & Total & $14(28.57)$ & $10(34.48)$ & $24(30.76)$ \\
\hline \multirow{4}{*}{$\begin{array}{l}\text { Uterine } \\
\text { factor }\end{array}$} & Fibroid & $3(6.12)$ & $2(6.89)$ & $5(6.41)$ \\
\hline & Mullerian & $2(4.08)$ & $1(3.44)$ & $3(3.84)$ \\
\hline & Hypoplastic & $1(2.04)$ & 0 & $1(1.28)$ \\
\hline & Total & $6(12.24)$ & $3(10.34)$ & $9(11.53)$ \\
\hline \multirow{4}{*}{$\begin{array}{l}\text { Peritoneal } \\
\text { factor }\end{array}$} & Endometriosis & $4(8.16)$ & $4(13.79)$ & $8(10.25)$ \\
\hline & Pelvic adhesions & $3(6.122)$ & $2(6.89)$ & $5(6.41)$ \\
\hline & Tuberculosis & $6(12.24)$ & 0 & $6(7.69)$ \\
\hline & Total & $13(26.53)$ & $6(20.68)$ & $19(24.35)$ \\
\hline
\end{tabular}

Table 3: Hysterolaparoscopically identified causative factors of infertility.

\begin{tabular}{|lllllll|}
\hline \multirow{2}{*}{ Causes of infertility } & \multicolumn{2}{l}{ Primary $(\mathbf{N}=\mathbf{4 9})$} & \multicolumn{2}{c|}{ Secondary $(\mathbf{N}=\mathbf{2 9})$} & \multicolumn{2}{c|}{ Total $(\mathbf{N}=\mathbf{7 8})$} \\
\cline { 2 - 8 } & Number & $\%$ & Number & $\%$ & Number & $\%$ \\
\hline Uterine factor & 13 & 26.53 & 7 & 2.41 & 20 & 25.64 \\
\hline Tubal factor & 13 & 26.53 & 9 & 3.10 & 22 & 28.20 \\
\hline Ovarian factor & 22 & 44.89 & 9 & 3.10 & 30 & 38.46 \\
\hline Peritoneal factor & 13 & 26.53 & 6 & 2.06 & 19 & 24.35 \\
\hline Unexplained & 9 & 18.36 & 9 & 3.10 & 18 & 23.07 \\
\hline
\end{tabular}

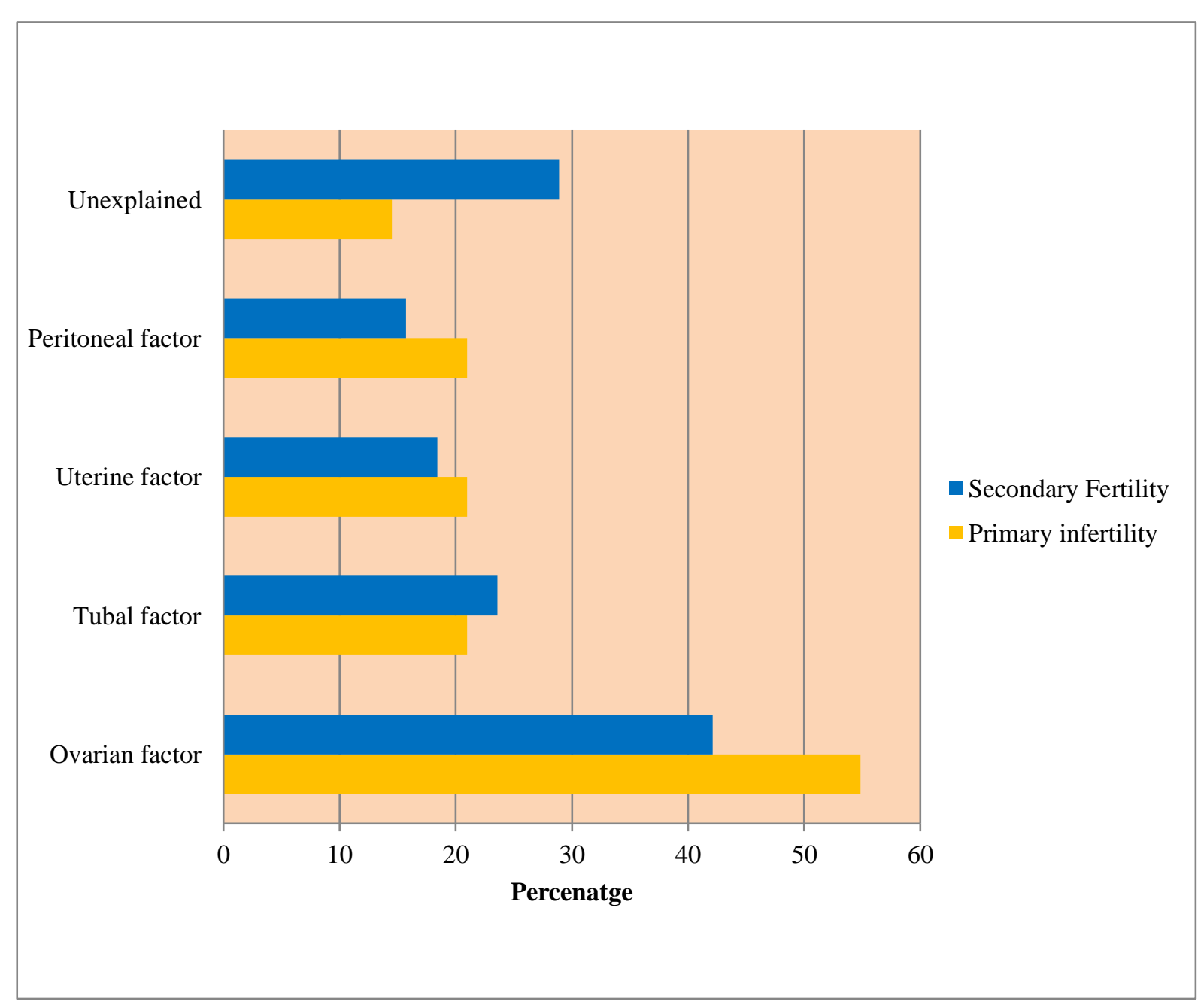

Figure 3: Causes of infertility. 


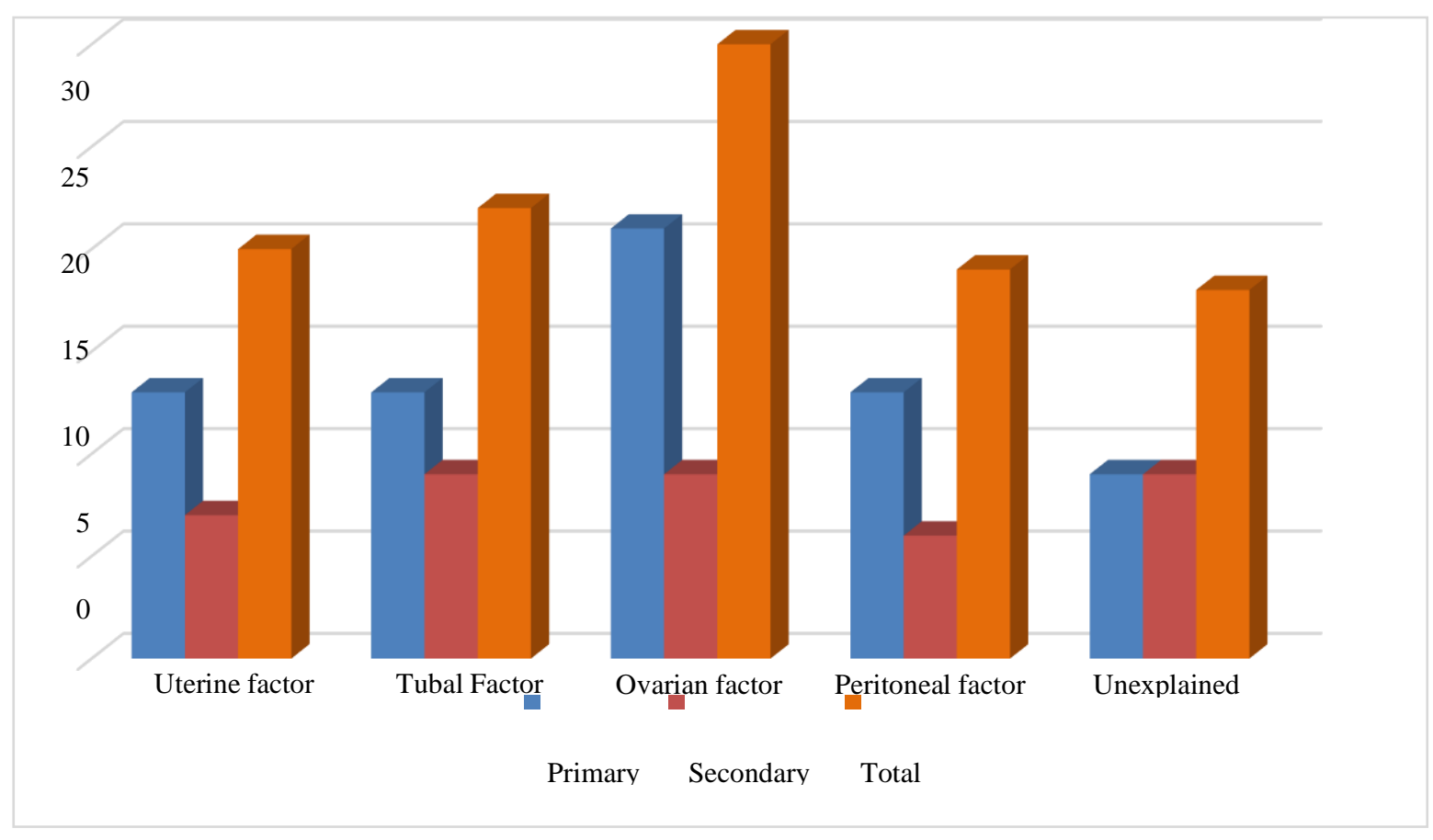

Figure 4: Hyster laparoscopically identified causative factors of infertility.

In our study, $39 \%$ of the infertile women had normal BMI while $61 \%$ of women had a high BMI. 36 women were overweight in which 22 were of the primary infertility and 14 were of the secondary infertility group. 25 infertile women were obese, of which 17 were primary and 8 were secondary infertile women.

Most women with secondary infertility had previous history of abortions, 20 of 38 cases (52.63\%). Out of these 20 cases, 18 cases had spontaneous abortions and 2 cases had induced abortions. Out of 18 women with prior spontaneous abortions, 12 cases had a history of check curettage.

Out of 100 cases, 50 women had menstrual abnormalities while a normal menstrual pattern was seen in rest 50 cases. Out of 100 cases, 40 women had PCOS. 27 (67.5\%) were primary infertile and $13(32.5 \%)$ were secondary infertile women.

Hypothyroidism was found to be the leading endocrinological abnormality in our study. 25 infertile women had hypothyroidism, of which 11 were primary and 14 secondary infertile women and 3 infertile women had hyperprolactinemia, 2 of these were primary infertility and 1 was secondary infertility.

Out of 100 cases, 17 cases had high day 2/3 FSH levels of more than 10 . Of these 9 were women with primary infertility and 8 were secondary infertile women. Low anti-mullerian hormone (AMH) levels were found in 7 infertile women of which 4 were primary and 3 secondary infertile women. Women with low AMH levels had associated high FSH levels. The FSH level in patients with normal AMH (mean and SD) is 7.11 \pm 6.42 . The FSH level in patients with low AMH (mean and SD) 14.99 \pm 7.88 . $(\mathrm{p}=0.003,<0.05)$.

Table 1 represents information about etiology of infertility and graphically presented in Figure 3. Out of 100 cases, ovarian factor was $50 \%$, uterine factors $20 \%$, tubal factors $22 \%$, peritoneal factors $19 \%$ and unexplained infertility was $20 \%$.

Out of 100 cases, 22 cases conceived with the initial treatment and did not need recourse to hysterolaparoscopy. Out of 100, 78 cases were planned for hysterolaparoscopy with chromopertubation.

Table 2 represents findings of all the infertile women who underwent laparoscopy. More than 1 factor was detected in many women. 5 cases had both uterine and tubal abnormalities, 4 cases had uterine and ovarian abnormalities, 2 cases had uterine and peritoneal factors, 4 cases had combined ovarian and peritoneal factors, 3 had combined ovarian and tubal abnormalities, 3 cases had tubal and peritoneal factors and 4 cases had combined ovarian, tubal and peritoneal factors and 1 case had uterine, tubal and peritoneal factor. In 20 cases out of 78 , no abnormality was found by laparoscopy and the cause of infertility was unexplained.

\section{DISCUSSION}

The incidence of primary infertility was $62 \%$ and that of secondary infertility was $38 \%$ which correlates with the studies conducted by Duignan et al $77 \%$ and $23 \%$ and Templeton et al $74.9 \%$ and $25.1 \%$ for primary and secondary infertility, respectively. ${ }^{4,5}$ 
The mean age of the infertile women was 28.13 years; for primary infertility, 27.53 years and for secondary infertility, 29.10 years. In present study majority of women with primary infertility $(45.16 \%)$ belong to $21-25$ years age group which is comparable to study conducted by Sortey et al (41.5\%) and Pal et al (42\%). ${ }^{6,7}$ And also majority of secondary infertility belongs 26-30 age group $(44 \%)$ in present study is quite similar to a study conducted by Sortey et al $(43.5 \%){ }^{6}$

Duration of infertility was 1-5 years in a majority of infertile women (66\%) in present study. A study conducted by Archana et al duration of infertility was $1-5$ years is seen in $74 \%$ patients which is slightly higher than present study. ${ }^{8}$

In present study hypothyroidism was seen in $25 \%$ infertile women which is almost similar to the observation of study conducted by Verma et al (23.9\%). ${ }^{9}$ Different causes of infertility were studied. The study shows ovarian factors $(50 \%)$ was most common factor for infertility followed by tubal factors (22\%), followed by uterine factors (20\%) and followed by peritoneal factors (19\%). PCOS was most common ovarian factor and seen in $23.04 \%$ patients in present study which is similar $(26 \%)$ to a study conducted by Nandhini et al. ${ }^{10}$ Bilateral tubal block (12.86\%) was most common tubal factor causing infertility which is similar (12.6\%) to study conducted by Bhide et al. ${ }^{11}$

In our study in $20 \%$ patients uterine factors were cause of infertility which is almost $(20.9 \%)$ same to study conducted by Hema et al. ${ }^{12}$ Our study showed that the incidence of mullerian tract anomaly was 8 (10.25\%) and was the main uterine pathology detected. This is in parallel with the findings of Sholapurkar et al, Sud et al and Prabhu et al. ${ }^{13-15}$ Endometriosis was most common pelvic factors causing infertility whereas in study conducted by Hema et al. ${ }^{12}$ Pelvic adhesions was most common pelvic factor causing infertility.

\section{CONCLUSION}

The leading cause of infertility is an ovarian factor, in which PCOS is the most common cause in both primary and secondary infertile women, followed by tubal, uterine, peritoneal and endocrinological factors.

PCOS was found as a contributing factor in both primary and secondary infertility, maybe because of increase in sedentary lifestyle and physical inactivity and the study population is from an urban background.

Funding: No funding sources Conflict of interest: None declared

Ethical approval: The study was approved by the Institutional Ethics Committee

\section{REFERENCES}

1. Hoffman BL, Schorge JO, Bradshaw KD, Halvorson LM, Schaffer JI, Corton MM. William's Gyneacology. 3rd ed. New York: McGraw Hill; 2017: 427.

2. Roupa Z, Polikandrioti M, Sotiropoulou P, Faros E, Koulouri A, Wozniak G, et al. Causes of infertility in women at reproductive age. Health Sci J. 2009;3(2):80-7.

3. Cooper TG, Noonan E, Eckardstein SN. World Health Organization reference values for human semen characteristics. Hum Reprod Update. 2010;16(3):23145.

4. Duignan NM, Jordan JA, Coughlan BM, LoganEdwards R. One thousand consecutive cases of diagnostic laparoscopy. J Obst Gynecol Br C Wealth. 1972;79(11):1016-24.

5. Templeton AA, Kerr MG. An assessment of laparoscopy as the primary investigation in the sub fertile female. Br J Obst Gynecol, 1977:84(10):760-2.

6. Sortey KD, Dhurandhar J. Laparoscopic evaluation of infertility. J Obstet Gynaecol India. 1989;39:809-11.

7. Pal M, Devgun P, Chalana H, Kaur H, Biswas A, Sen S. A study of prevalence and socio-demographic profile of infertile couples in field practice area of a tertiary care centre, Amritsar, Punjab, India. Int J Community Med Public Health. 2016;3(6):1472-6.

8. Daddenavar AV, Daddenavar VM. Infertility analysis by hysterolaparoscopy. Int $\mathrm{J}$ Reprod Contracept Obstet Gynecol. 2016;5(5):1472-5

9. Verma I, Sood R, Juneja S, Kaur S. Prevalence of hypothyroidism in infertile women and evaluation of response of treatment for hypothyroidism on infertility. Int J Appl Basic Med Res. 2012;2(1):17-9.

10. Nandhini V, Murugalakshmi. Role of diagnostic hysterolaparoscopy in primary infertility. IOSR J Dent Med Sci. 2016;15(8):25-8.

11. Bhide AG. Laparoscopic evaluation of the etiopathology of infertility. J Obstet Gynecol India. 1990;40:680-2.

12. Hema KR, Lalitha HS. Evaluation of role of laparoscopy in determining etiology of infertility. Int J Reprod Contracept Obstet Gynecol. 2017;6(12):5322-6.

13. Sholapurkar ML. Primary amenorrhoea. A clinical and laparoscopic study. J Obst Gynaecol India. 1986;36:1052.

14. Sud K, Malan R, Saxena P, Thakur K. Analysis of 300 diagnostic laparoscopies. J Obstet Gynaecol India. 1987;37:156.

15. Prabhu JR, Sivaraman R, Srinivasan O, Rajarathnam, S. Diagnostic laparoscopy. A review of 800 case. The J Obstet Gynaecol India. 1988;38:205.

Cite this article as: Shinde KP, Krovi N, Dhutraj PG. Study of factors contributing to female infertility. Int J Reprod Contracept Obstet Gynecol 2021;10:2591-5. 